\title{
RECONHECIMENTO DO DIREITO AOS BENEFÍCIOS PREVIDENCIÁRIOS PARA DEPENDENTES QUE POSSUEM RELAÇÃO HOMOAFETIVA COM O SEGURADO
}

\author{
Waleska Mendes Cardoso*
}

\begin{abstract}
RESUMO:A liberdade individual tem dado oportunidade de revelar o relacionamento homoafetivo, de modo que este tema está presente nas discussões da sociedade. Porém, a legislação brasileira não acompanha esse avanço, pois ainda não positivou dispositivo que regula diretamente os casais homoafetivos. Não há previsão legal expressa para amparar o direito dos parceiros homoafetivos à percepção de benefícios previdenciários. De mesmo modo, a jurisprudência se posiciona no sentido de negar benefícios previdenciários ao companheiro homossexual. Diante disto, deve-se fazer a interpretação dos dispositivos legais conforme os princípios constitucionais, de modo a cumprir os fundamentos do Estado brasileiro.
\end{abstract}

PALAVRAS-CHAVE: Relação homoafetiva. Ausência normativa. Direito Previdenciário. Princípios constitucionais.

ABSTRACT: The individual freedom has given chance to disclose the homosexual relationship, in way that this subject is present in the society discussions. However, the Brazilian legislation does not follow this advance, therefore it doesn't create the norm that regulates directly the homossexual couples. There's no express legal forecast to support the right of the homossexual partners to the perception of "previdenciários" benefits. In same way, the jurisprudence is located in the direction to deny "previdenciários" benefits to the homosexual partner. In this way, the interpretation of the legal devices must be made according to the constitutional principles, in order to fulfill the beddings of the Brazilian State.

KEY-WORDS: Homossexual relationchip. Normative absence. Previdenciário right. Principles constitutional.

*A autora é acadêmica do oitavo semestre do curso de Direito da Universidade Federal de Santa Maria.

\section{INTRODUÇÃO}

A sociedade brasileira, berço de diversidade, abarca também o preconceito. A cultura do país, a desigualdade econômica e o próprio ordenamento jurídico dão margem a esta situação, que é por muitos repelida, mas que é normal para muitas outras pessoas.

Não é de hoje que a homoafetividade é conhecida da sociedade, desde muito tempo existem relações desse tipo. O que se está a referir é que o relacionamento homoafetivo não é um efeito do mundo moderno, mas sim, reflexo da evolução da sociedade no que diz respeito à liberdade individual.

Em ordenamentos existentes no mundo atual, quase não se faz referência a esse tipo de relacionamento, restando excluídos estes indivíduos da sociedade civil, principalmente no que se refere ao direito de família, previdenciário e sucessões. $\mathrm{Na}$ legislação brasileira não é diferente. 
O ordenamento jurídico, ao criar normas, deve acompanhar os fatos e os valores sociais, e regular ao máximo as relações humanas, para dar segurança jurídica aos indivíduos, isolados e como grupo social.

$\mathrm{Na}$ contra-mão do reconhecimento dos relacionamentos homoafetivos, a jurisprudência se manifesta de forma a não admitir as relações entre pessoas do mesmo sexo, para negar os benefícios previdenciários aos quais o companheiro tem direito. Assim, o presente trabalho visa a proposição do reconhecimento do companheiro homoafetivo para efeitos da incidência do Art. 16, I da Lei 8.213, que institui os benefícios previdenciários, de forma isonômica e equânime aos outros dependentes.

\section{O TRATAMENTO DO ORDENAMENTO JURÍDICO A RESPEITO DA HOMOAFETIVIDADE}

A Constituição Federal, nos primeiros artigos, concatena uma série de princípios basilares da sociedade brasileira, como igualdade, justiça, solidariedade.

É desejo da federação manter uma sociedade livre, justa e sem nenhum preconceito, de qualquer espécie ${ }^{1}$.

No entanto, a legislação, ao deixar alguns jurisdicionados à margem do direito, cria mais preconceitos do que os existentes. É o caso dos casais homossexuais, que ficam à margem da sociedade, e da legislação, pois não são reconhecidos como entidade familiar e têm uma infinidade de direitos não protegidos pelas normas existentes, simplesmente por serem diferentes.

De acordo com a Lei de Introdução ao Código Civil (LICC - Decreto-lei 4657/42), o juiz deve atender aos fins sociais a que a lei se destina e às exigências do bem comum ${ }^{2}$. Assim, quando for proferir uma decisão, o magistrado deve trazer a interpretação mais justa e que corresponda aos objetivos do sistema jurídico nacional.

Ainda pela Lei de Introdução ao Código Civil (que deve ser uma base para a aplicação de todas as leis do ordenamento jurídico brasileiro, não somente para o

\footnotetext{
${ }^{1}$ Artigo $1^{\circ}$ da Constituição da República Federativa do Brasil: “A República Federativa do Brasil [...] tem como fundamentos: $[\ldots]$;

III - a dignidade da pessoa humana;",

Artigo $3^{\circ}$ da CF/88: "Constituem objetivos fundamentais da República Federativa do Brasil:

I - construir uma sociedade livre, justa e solidária;

$[\ldots]$;

IV - promover o bem de todos, sem preconceitos de origem, raça, sexo, cor, idade e quaisquer outras formas de discriminação.'

Artigo $5^{\circ}$ da CF/88: "Todos são iguais perante a lei, sem distinção de qualquer natureza, garantindo-se aos brasileiros e aos estrangeiros residentes no País a inviolabilidade do direito à vida, à liberdade, à igualdade, à segurança e à propriedade, nos seguintes termos:" [...].

${ }^{2}$ Artigo $5^{\circ}$ da LICC (Decreto-lei 4657/42): "Na aplicação da lei, o juiz atenderá aos fins sociais a que ela se dirige e às exigências do bem comum.".
} 
Código Civil), o juiz deve "decidir o caso conforme a analogia, os costumes e os princípios gerais de direito", consoante a letra do artigo $4^{\circ 3}$.

Hoje, apenas por analogia ou de acordo com Princípios Gerais do Direito a união homossexual tem ganhado um tratamento mais condizente com a realidade. Mas, para alguns ramos autônomos do Direito, como o Penal ou o Previdenciário, não se admite a analogia como forma de interpretação dos casos fáticos. Destarte, está-se diante de um problema de interpretação normativa e surge o conflito entre princípios, quais sejam, o da legalidade e da igualdade.

\section{PRINCÍPIO DA LEGALIDADE, PRINCÍPIO INFORMADOR DO DIREITO PREVIDENCIÁRIO}

O Direito Previdenciário é um ramo do Direito Público, no qual se organiza o Regime Geral da Previdência Social. Este ramo da ciência jurídica regula a forma de contribuição dos segurados e os direitos a benefícios previdenciários destes e de seus dependentes.

Como ramo do Direito Público, o Direito Previdenciário pauta-se sobre o princípio da legalidade. O princípio da legalidade é a maior expressão da garantia do cidadão frente aos atos do Estado. Busca assegurar a igualdade e segurança dos indivíduos porquanto importa em tratamento equânime a todos os cidadãos, tratamento este decorrente das características próprias da lei: generalidade e abstração. Estas características impedem os fatais casuísmos, fonte principal das perseguições e dos favoritismos. Importa ainda o combate ao poder arbitrário do Estado, trazendo a segurança necessária para o convívio social.

Conforme Alexandre de Moraes,

O princípio da legalidade mais se aproxima de uma garantia constitucional do que de um direito individual, já que não tutela, especificamente, um bem da vida, mas assegura ao particular a prerrogativa de repelir as injunções que lhe sejam impostas por uma ou outra via que não seja a da lei (MORAES, 2006, p. 36).

Outra faceta do princípio da legalidade corresponde ao conteúdo da lei. $\mathrm{Na}$ aludida obra de A. de Moraes, o autor cita Eduardo Garcia de Enterría, concluindo que

não é qualquer comando ou preceito que se legitima, mas somente aqueles que se produzem dentro da Constituição e especialmente de acordo com a sua ordem

\footnotetext{
${ }^{3}$ Artigo $4^{\circ}$ da LICC (Decreto-lei 4657/42): "Quando a lei for omissa, o juiz decidirá o caso de acordo com a analogia, os costumes e os princípios gerais de direito.".
} 
de valores que, com toda a explicitude, [...] sirvam aos direitos fundamentais (ENTERRÍA, apud: MORAES, 2006, p. 36).

Desta feita, mesmo que o Direito Previdenciário deva seguir o princípio da legalidade, isto não significa que da omissão do legislador possa advir tratamento desigual entre as pessoas, indo de encontro aos direitos constitucionais.

Para que as normas do Direito Previdenciário sejam legítimas dentro da ordem jurídica nacional, devem, assim como todas as outras normas, ser lidas sob a luz dos princípios constitucionais, em especial os princípios da igualdade e dignidade da pessoa humana.

\section{A LEITURA CONSTITUCIONAL DAS NORMAS COMO FORMA DE INTERPRETAÇÃO JUSTA EM CASOS CONCRETOS}

Casos recorrentes na jurisprudência são os requerimentos de benefícios previdenciários, como a pensão por morte, para o companheiro homossexual supérstite. A Lei 8213/91 - lei dos benefícios previdenciários - traz em seu artigo $16^{4}$ a classe dos dependentes do beneficiário, que tem direito a receber a pensão do INSS no caso de morte do segurado.

Para a primeira classe de dependentes - cônjuge, companheiro(a), filhos não emancipados, de qualquer condição, até 21 anos, ou inválidos - basta que o companheiro comprove a relação de convivência, prescindindo da comprovação de dependência econômica, conforme se aduz da leitura do parágrafo $3^{\circ}$ do artigo 16 da Lei dos Benefícios Previdenciários. Desta forma, os dependentes integrantes da $1^{\text {a }}$ classe têm a dependência econômica presumida. Sendo que ao companheiro(a) basta a comprovação da existência de união estável.

Ocorre freqüentemente a improcedência destes requerimentos feitos por companheiro homossexual sobrevivente, pois a jurisprudência ou entende não ser previsto o benefício ao companheiro homossexual, ou entende que é necessária a comprovação da dependência econômica. Estas decisões, evidentemente, violam o

\footnotetext{
${ }^{4}$ Artigo 16 da Lei 8.213/91: "São beneficiários do Regime Geral de Previdência Social, na condição de dependentes do segurado: I - o cônjuge, a companheira, o companheiro e o filho não emancipado, de qualquer condição, menor de 21 (vinte e um) anos ou inválido; II - os pais;

III - o irmão não emancipado, de qualquer condição, menor de 21 (vinte e um) anos ou inválido; $[\ldots]$

$\S 3^{\circ}$ Considera-se companheira ou companheiro a pessoa que, sem ser casada, mantém união estável com o segurado ou com a segurada, de acordo com o $\S 3^{\circ}$ do art. 226 da Constituição Federal.

$\S 4^{\circ}$ A dependência econômica das pessoas indicadas no inciso I é presumida e a das demais deve ser comprovada.".
} 
artigo 16, inciso I da Lei 8213 de 1991, e estão em dissonância com o princípio da igualdade, o qual é base da Constituição Federal de 1988.

Alguns legalistas argumentam que a Constituição regulou a União Estável entre homem e mulher, sendo excluído da proteção legal o relacionamento homoafetivo. E este argumento é o principal óbice para a consecução da justiça nos casos concretos, pois a real justificativa está eivada de preconceito.

Decisões como esta são recorrentes no Judiciário ${ }^{5}$. A justificativa para tal entendimento se baseia no fato de que o dispositivo da Lei não trata de relacionamento homoafetivo.

Contudo, esta afirmação deve ser refutada, na medida em que a Lei prevê o benefício, independente de comprovação econômica, para companheiro(a), desde que comprovada a relação. O fato de não haver legislação que regulamente ou preveja uma união entre pessoas do mesmo sexo, não pode ser justificativa para o cometimento de tamanhas injustiças, que acentuam o preconceito na sociedade.

Jurisprudências já concederam a pensão por morte para companheiro homoafetivo supérstite, desde que comprovadas a união e a dependência econômica ${ }^{6}$. Esse entendimento é considerado por muitos um avanço, já que não existe previsão legal para a concessão pensão por morte ao parceiro homossexual, de forma que o juiz, ao concedê-lo, estaria sendo justo, inovando entendimentos.

Entretanto, estas decisões devem ser consideradas como retrocesso da justiça ou ao menos um avanço muito tímido, ao passo que não atendem ao princípio da

\footnotetext{
${ }_{5}^{5}$ APELACAO. RELACIONAMENTO HOMOSSEXUAL. INEXISTENCIA DE UNIAO ESTAVEL. IMPOSSIBILIDADE DO SOBREVIVENTE SE BENEFICIAR DA HERANCA DO FALECIDO NOS TERMOS DO ARTIGO 2, INCISO III, DA LEI 8.971/94. O RELACIONAMENTO HOMOSSEXUAL DE DOIS HOMENS, NAO SE CONSTITUI EM UNIAO ESTAVEL PARA OS EFEITOS DO PAR. 3, DO ARTIGO 226, DA CONSTITUICAO FEDERAL E LEIS 8.971/94 E 9.278/96. A UNIAO ESTAVEL PARA SER RECONHECIDA COMO ENTIDADE FAMILIAR, EXIGE A CONVIVENCIA DURADOURA, PUBLICA E CONTINUA DE UM HOMEM E UMA MULHER, ESTABELECIDA COM OBJETIVO DE CONSTITUICAO DE FAMILIA, INCLUSIVE COM A POSSIBILIDADE DE SUA CONVERSAO EM CASAMENTO. AS OUTRAS ESPECIES DE UNIOES INFORMAIS, QUE NAO SE ENCAIXEM NA NOCAO DE COMPANHEIRISMO, INCLUSIVE ENTRE PESSOAS DO MESMO SEXO, ESTAO ABRANGIDAS PELA SUMULA 380, DO SUPREMO TRIBUNAL FEDERAL. (SEGREDO DE JUSTICA). (Apelação Cível N ${ }^{\circ}$ 599348562, Oitava Câmara Cível, Tribunal de Justiça do RS, Relator: Antônio Carlos Stangler Pereira, Julgado em 11/10/2001).

RELACIONAMENTO HOMOSSEXUAL. INEXISTÊNCIA DE UNIÃO ESTÁVEL. 1. A união estável para ser reconhecida como entidade familiar, exige a convivência duradoura, pública e contínua de um homem e uma mulher, estabelecida com objetivo de constituição de família, inclusive com a possibilidade de sua conversão em casamento, o que não ocorre na espécie. 2. Não havendo sequer situação fática assemelhada a um casamento, sem que o par sequer tenha morado sob o mesmo teto, não há como reconhecer a pretendida união homossexual com o objetivo de estender-lhe os efeitos próprios de uma união estável. Recurso desprovido, por maioria. (SEGREDO DE JUSTIÇA) (Apelação Cível No 70009888017, Sétima Câmara Cível, Tribunal de Justiça do RS, Relator: Sérgio Fernando de Vasconcellos Chaves, Julgado em 27/04/2005).

${ }^{6}$ CONSTITUCIONAL. PREVIDENCIÁRIO E PROCESSO CIVIL. NORMAS CONSTITUCIONAIS. CF, ART. 226, § $3^{\circ}$. INTEGRAÇÃO HOMOSSEXUAIS. INSCRIÇÃO DE COMPANHEIROS HOMOSSEXUAIS COMO DEPENDENTES NO REGIME GERAL DE PREVIDÊNCIA SOCIAL. AÇÃO CIVIL PÚBLICA. INEXISTÊNCIA DE USURPAÇÃO DE COMPETÊNCIA PARA O CONTROLE CONCENTRADO DE CONSTITUCIONALIDADE. DIREITOS INDIVIDUAIS HOMOGÊNEOS. TITULARIDADE DO MINISTÉRIO PÚBLICO FEDERAL. AMPLITUDE DA LIMINAR. ABRANGÊNCIA NACIONAL. LEI No 7.347/85, ART. 16, COM A REDAÇÃO DADA PELA LEI No 9.494/97. 1. As normas constitucionais, soberanas embora na hierarquia, são sujeitas a interpretação. Afasta-se a alegação de que a espécie cuida de inconstitucionalidade de lei; o que ora se trata é de inconstitucionalidade na aplicação da lei; o que se cuida não é de eliminar por perversa a disposição legal; sim, de ampliar seu uso, por integração.

2. É possível a abrangência de dependente do mesmo sexo no conceito de companheiro previsto no art. 226 , $\S 3^{\circ}$, da Constituição Federal, frente à Previdência Social, para que o homossexual que comprovadamente vive em dependência de outro não fique relegado à miséria após a morte de quem lhe provia os meios de subsistência.

(Agravo de Instumento $N^{\circ}$ 2000.04.044144-0. Sexta Turma, TFR $4^{\text {a }}$ Região, Relator: Luiz Carlos de Castro Lugon, Julgado em 27/06/2000). (Grifouse)
} 
igualdade, trazido pela Constituição Federal, em inúmeros artigos, nem aos objetivos da República, conforme o artigo $3^{\circ}$ da CF de 1988, quais sejam, a construção de uma sociedade livre, justa e solidária e a promoção do bem de todos sem preconceitos de origem, raça, sexo, cor, idade e quaisquer outras formas de discriminação.

A decisão é um avanço se forem levadas em consideração as atitude e postura preconceituosas do homem, na medida em que ele reage negativamente a qualquer comportamento diverso do da maioria. A partir dessa conjectura, a decisão é inovadora, posto que vai de encontro ao pensamento majoritário.

No entanto, esta decisão é injusta, se forem considerados os princípios constitucionais já citados, pois o homossexual é igual a todos, em relação a direitos e obrigações. E é igualmente injusto o não reconhecimento, no mundo jurídico, da sua escolha sexual. Assim como os indivíduos têm liberdade de escolher a religião (artigo $5^{\circ}$, inciso VI, CF/88) e esta escolha deve ser respeitada, é natural que o homem, como ser livre e independente, possa decidir se deseja manter uma relação de afeto e cumplicidade com outra pessoa do mesmo sexo.

Partindo-se do pressuposto o qual não se admite no ordenamento jurídico um companheiro homossexual, por não haver específica menção na lei, estar-se-á dando um tratamento desigual a pessoas que, por mais esse motivo, acabam sofrendo com o preconceito e a marginalização.

Desta maneira, se não for possível ou admissível para muitos juristas a utilização da analogia e dos princípios constitucionais para caracterizar a união homossexual como união estável - do modo em que esta vem disciplinada na $\mathrm{CF} / 88$ especificamente para o Direito Previdenciário, ainda assim, a união entre pessoas do mesmo sexo pode ser considerada outra entidade familiar podendo ser chamada de “União Homoafetiva”, já que é considerada uma sociedade de fato, entretanto ainda não é uma família para o direito brasileiro.

A regulamentação das uniões homossexuais é possível mediante a interpretação analógica da norma do artigo 226, $\$ 3^{\circ}$ da Constituição Federal ${ }^{7}$ e de sua integração à realidade social. Tal leitura deve ser promovida tanto pelos operadores do Direito - Juízes, Desembargadores, doutrinadores - quanto pela sociedade, pois "as vontades populares acabam por levar a efeito uma interpretação da Constituição" (BASTOS, 2002, p.141).

\footnotetext{
${ }^{7}$ Artigo 226, CF/88: "A família, base da sociedade, tem especial proteção do Estado". $[\ldots]$

$\S 3^{\circ}$ - "Para efeito da proteção do Estado, é reconhecida a união estável entre o homem e a mulher como entidade familiar, devendo a lei facilitar a sua conversão em casamento.".
} 


\section{SOLUÇÃO A SER ADOTADA PELOS OPERADORES DO DIREITO QUANTO À INTERPRETAÇÃO DAS NORMAS}

O ordenamento jurídico é uno e harmonioso entre si. Quando há antinomias, o direito traz opções para resolvê-las. Quando há omissões, a lei autoriza a completá-las, segundo os critérios de interpretação e integração de normas. Quando há lacunas e obscuridades, o direito as soluciona por meio de analogias, princípios gerais do direito e dos costumes ${ }^{8}$. Interpretação essa que, aos olhos de Kelsen (2003, p.387), é "uma operação mental que acompanha o processo de aplicação do Direito no seu progredir".

A interpretação da norma deve ser feita pelo aplicador do Direito quando julga a incidência da lei no caso concreto, mas ela também deve ser feita por uma pessoa privada - um particular - e pela ciência jurídica, doutrinadores (KELSEN, 2003, p.388). Dessa forma, não cabe somente ao magistrado dizer o direito, e sim a todos os destinatários compreendê-la, visto que são obrigados a observá-la.

A interpretação das normas deve ser feita com o intuito de saber qual o conteúdo deve ser dado à norma individual de uma sentença, norma esta a ser deduzida da norma geral da lei, na sua aplicação no caso concreto. Ao interpretar a norma, tentase inferir o que o legislador quis dizer, qual foi sua intenção ao criar o dispositivo legal, qual o espírito da norma.

Segundo o Dr. Anderson Sant'Ana Pedra, doutorando em Direito Constitucional pela PUC/SP, em artigo publicado na Internet,

A norma jurídica contém elasticidade para corresponder às diferentes exigências que variam no tempo e produzir efeitos mesmo quando se alteraram os fatos e os valores em razão dos quais surgiu, pois a norma permanece em evolução, respondendo a novas necessidades, a novos problemas oriundos da mutação dos tempos, aduzindo significações novas que seu elaborador não poderia ter pressentido. Por isso que se afirma que a norma é mais inteligente que seu criador, sobrevive ao tempo, enquanto este é efêmero. ${ }^{9}$

Evidente que, se uma norma foi aditada ao ordenamento jurídico há mais de meio século, a vontade do legislador não está de acordo com as necessidades e realidade atuais. Tanto sua vontade está ultrapassada, quanto o significado dado ao conceito normativo utilizado está obsoleto. E como o processo de criação de normas é cheio de

\footnotetext{
${ }^{8}$ A própria Lei de Introdução ao Código Civil, decreto-lei n ${ }^{\circ} 4657$, de 4 de setembro de 1942, como já referido, dispõe em seu artigo $4^{\circ}$, in verbis: "quando a lei for omissa, o juiz decidirá o caso de acordo com a analogia, os costumes e os princípios gerais do direito".

PEDRA, Anderson Sant'Ana. Os fins sociais da norma e os princípios gerais de direito. Artigo publicado em <http://jus2.uol.com.br/doutrina/texto.asp?id=3762>. O autor é Doutorando em Direito Constitucional pela PUC/SP, Mestre em Direito pela FDC/RJ, Especialista em Direito Público pela Consultime/Cândido Mendes/ES, Chefe da Consultoria Jurídica do TCEES, Professor em gradu ação e em pósgraduação de Dir. Constitucional e Administrativo, Consultor do DPCC Direito Público Capacitação e Consultoria, Advogado em Vitória/ES.
} 
formalismo e, conseqüentemente moroso, as normas que são atualmente aplicadas são obsoletas e não se coadunam com as necessidades e os anseios da sociedade.

\subsection{Garantia de direitos aos homossexuais a partir de interpretação sistêmica do ordenamento jurídico}

Diversas normas contêm termos que necessitam ser preenchidos por conceitos. O conceito vazio de companheiro, também é exemplo. A compreensão de seu sentido é necessária para a devida compreensão da lei. O legislador, ao criar a norma, utilizou-se da palavra companheiro em inúmeros dispositivos legais. Para citar, o artigo 1724 e 1725 do CC/02, que integram o Título III do Direito de Família ${ }^{10}$, qual seja, Da União Estável.

Para alguns juristas, este conceito foi preenchido pela própria Constituição Federal, no artigo 226. O artigo 226, $\S 3^{\circ}$ da Constituição Federal dispõe: "Para efeito da proteção do Estado, é reconhecida a união estável entre o homem e a mulher como entidade familiar, devendo a lei facilitar sua conversão em casamento". Ou seja, os integrantes da União Estável são chamados companheiros, da mesma forma que são os cônjuges que compõem a instituição familiar mais comum: o casamento.

Entretanto, pode-se preencher este conceito de forma diversa, inclusive com os dispositivos constitucionais. Logo após, o $§ 7^{\circ}$ do artigo 226 dispõe:

Fundado nos princípios da dignidade da pessoa humana e da paternidade responsável, o planejamento familiar é livre decisão do casal, competindo ao Estado propiciar recursos educacionais e científicos para o exercício desse direito, vedada qualquer forma coercitiva por parte de instituições oficiais ou privadas. (Grifou-se)

O Código Civil de 10 de janeiro de 2002, lei ordinária, portanto infraconstitucional, não tratou de forma diversa a União Estável como entidade familiar, a qual se dá, segundo a Constituição Federal, somente entre homem e mulher, omitindose em relação à união homossexual.

O Código foi formulado segundo os princípios da eticidade, operatividade e sociabilidade, contrariando os costumes e a realidade que inspiraram o Código Civil de 1.916. Diz-se que o Diploma Civil não tratou de união homossexual porque a

\footnotetext{
${ }^{10}$ Artigo 1724 do Código Civil de 2002: "As relações pessoais entre os companheiros obedecerão aos deveres de lealdade e assistência, e de guarda, sustento e educação dos filhos.".

Artigo 1725 do mesmo diploma legal: "Na união estável, salvo contrato escrito entre os companheiros, aplica-se às relações patrimoniais, no que couber, o regime da comunhão parcial de bens.".
} 
Constituição Federal estabeleceu somente a união entre homem e mulher, limitando a vontade dos legisladores infraconstitucionais.

Contudo, ao tratar no parágrafo sétimo de outras entidades familiares, a Constituição abriu espaço para união entre homossexuais. Desta forma, o Código Civil poderia ter legislado sobre a matéria, mas pecou pela falta.

Diante do problema da "inexistência de previsão legal" a respeito da união entre pessoas do mesmo sexo, aduz-se que o conceito utilizado pela lei para companheiro engloba somente pessoas do sexo oposto, ou seja, homem que mantém União Estável com mulher, como expressamente foi tratado pela Carta Magna.

A palavra "companheiro" também é utilizada, como viu-se acima, no inciso I do artigo 16 da Lei 8213/91. Assim, grande parte da doutrina não entende integrar este conceito as pessoas do mesmo sexo que mantém relação afetiva.

No entanto, esta interpretação não condiz com a atualidade e demonstra visão atrasada e preconceituosa com a qual pessoas são julgadas todos os dias no Brasil.

Alguns autores do Direito Previdenciário estão evoluindo em suas compreensões sobre o tema. É o caso de Ivan Kertzman (2005, p.263), quando refere com propriedade que integram a primeira classe de dependentes "a companheira ou companheiro, que, embora não casados oficialmente, vivam juntos com a intenção de constituir família, tendo os mesmos direitos dos cônjuges, incluindo, aqui, os parceiros homossexuais".

$\mathrm{O}$ rol das entidades familiares previstas pela $\mathrm{CF}$, em seu artigo 226 , não é taxativo, pois, se assim o fosse, tal dispositivo constitucional seria inconstitucional, visto que a própria Constituição Federal dispõe: no artigo $1^{\circ}$, III, sobre o princípio da dignidade humana; no artigo $5^{\circ}$, sobre o princípio da igualdade; no artigo $3^{\circ}$, I e IV, sobre o princípio democrático de direito, que se consolida através da convivência numa sociedade livre, justa, solidária e pluralista, pressupondo a possibilidade de convivência de interesses diferentes, sem preconceitos de origem, raça, sexo, cor, idade e quaisquer outras formas de discriminação.

Assim, é possível a criação de outras entidades familiares, como a família com avós e netos, e a família homossexual.

Segundo entendimento do Dr. Juiz Roberto Arriada Lorea, da $2^{\mathrm{a}}$ Vara de Família e Sucessões da Comarca de Porto Alegre, ao proferir sentença em 14 de fevereiro de 2005, julgando procedente uma ação de dissolução de união estável entre 
casal homossexual, não só a união estável entre homossexuais é possível como também o casamento, pois

[...] da leitura do art. 226, $\S 3^{\circ}$ da $\mathrm{CF}$, não decorre a conclusão 'somente entre homens e mulheres', ao contrário, não veda a possibilidade da proteção jurídica das relações estáveis entre pessoas do mesmo sexo. Assim, nos casos de vazio normativo, deve o juiz decidir de acordo com a analogia, os costumes e os princípios gerais do Direito. ${ }^{11}$

No corpo da sentença, o julgador para embasar sua decisão, registra o reconhecimento da união estável homossexual pelo Tribunal Superior Eleitoral conforme ementa:

REGISTRO DE CANDIDATO. CANDIDATA AO CARGO DE PREFEITO. RELAÇÃO ESTÁVEL HOMOSSEXUAL COM A PREFEITA REELEITA DO MUNICÍPIO. INELEGIBILIDADE. ART. $14, \S 7^{\circ}$, DA CONSTITUIÇÃO FEDERAL. Os sujeitos de uma relação estável homossexual, à semelhança do que ocorre com os de relação estável, de concubinato e de casamento, submetem-se à regra de inelegibilidade prevista no art. $14, \S 7^{\circ}$, da Constituição Federal. Recurso a que se dá provimento. (ACÓRDÃo 24564 VISEU - PA 01/10/2004 Relator(a) GILMAR FERREIRA MENDES Relator(a) designado(a) Publicação PSESS - Publicado em Sessão, Data 01/10/2004).

\section{E conclui da seguinte maneira:}

[...] atribuir-se tratamento diferenciado aos jurisdicionados homossexuais seria um desrespeito ao analisado princípio da igualdade. Nesse sentido, seria um absurdo aceitar que o Poder Judiciário fechasse seus olhos não só para as modificações de nossa sociedade, como para a Constituição Federal que rege nossa nação. Buscando na "falta de legislação expressa" razão suficiente para julgar injustamente fatos que ocorrem entre "minorias sociais" que já são constantemente discriminadas.

A partir deste julgado, outros magistrados seguiram a mesma linha de decidir.

É o que se evidencia quando da análise das jurisprudências a seguir.

PREVIDENCIÁRIO. CONCESSÃO DE PENSÃO POR MORTE. UNIÃO ESTÁVEL ENTRE CASAL HOMOSSEXUAL COMPROVADA. HONORÁRIOS ADVOCATÍCIOS.

1. Na vigência da Lei $n^{\circ} 8.213 / 91$, dois são os requisitos para a concessão de benefício de pensão por morte, quais sejam, a qualidade de segurado do instituidor e a dependência dos beneficiários que, se preenchidos, ensejam o seu deferimento. 2. Faz jus à percepção de pensão por morte o companheiro homossexual se demonstrada a união estável com o ex-segurado até a data do óbito. [...] (Apelação Cível N 2005.71.10.001969-0/RS, Sexta Turma, TFR $4^{\text {a }}$ Região, Relator: Des. Federal João Batista Pinto Silveira, Julgado em 28/02/2007).

${ }^{11}$ Decisão na íntegra disponível em:

$<$ http://www.tj.rs.gov.br/site_php/noticias/mostranoticia.php?assunto=1\&categoria=1\&item=30873>. 
CONSTITUCIONAL. PREVIDENCIÁRIO. PENSÃO POR MORTE. CONCESSÃO. COMPANHEIRO. UNIÃO HOMOSSEXUAL. REALIDADE FÁTICA. TRANSFORMAÇÕES SOCIAIS. EVOLUÇÃO DO DIREITO. PRINCÍPIOS CONSTITUCIONAIS DE IGUALDADE. ARTIGOS $3^{\circ}$, IV E $5^{\circ}$. DEPENDÊNCIA ECONÔMICA PRESUMIDA. CORREÇÃO MONETÁRIA. JUROS DE MORA. HONORÁRIOS ADVOCATÍCIOS.

1. A realidade social atual revela a existência de pessoas do mesmo sexo convivendo na condição de companheiros, como se casados fossem. 2 . O vácuo normativo não pode ser considerado obstáculo intransponível para o reconhecimento de uma relação jurídica emergente de fato público e notório. 3 . O princípio da igualdade consagrado na Constituição Federal de 1988, inscrito nos artigos $3^{\circ}$, IV, e $5^{\circ}$, aboliram definitivamente qualquer forma de discriminação. 4. A evolução do direito deve acompanhar as transformações sociais, a partir de casos concretos que configurem novas realidades nas relações interpessoais. 5. A dependência econômica do companheiro é presumida, nos termos do $\S 4^{\circ}$ do art. 16 da Lei $n^{\circ} 8.213 / 91$. 6. Estando comprovada a qualidade de segurado do de cujus na data do óbito, bem como a condição de dependente do autor, tem este o direito ao benefício de pensão por morte, o qual é devido desde a data do ajuizamento da ação, uma vez que o óbito ocorreu na vigência da Lei $\mathrm{n}^{\circ}$ 9.528/97. [...]. Apelações providas. (Apelação Cível $\mathrm{N}^{\circ}$ 2000.04.01.073643-8, Sexta Turma, TRF $4^{\mathrm{a}}$ Região, Relator Nylson Paim de Abreu, Publicado em 10/01/2001).

ADMINISTRATIVO. PROCESSUAL CIVIL. PENSÃO POR MORTE DE SERVIDOR PÚBLICO. REGIME DE UNIÃO ESTÁVEL. COMPANHEIRO HOMOSSEXUAL. RECONHECIMENTO DO DIREITO. LITISCONSÓRCIO PASSIVO NECESSÁRIO. HABILITAÇÃO DA EX-CÔNJUGE. BENEFICIÁRIA DE PENSÃO ALIMENTÍCIA. RATEIO EM PARTES IGUAIS. DIES A QUO DO BENEFÍCIO. CORREÇÃO MONETÁRIA. JUROS DE MORA. [...] A impossibilidade jurídica do pedido revela-se como uma forma de limitação à regra geral, nas hipóteses em que a demanda se mostra incompatível com o ordenamento jurídico. Não é o caso dos autos, já que a tutela jurisdicional não encontra proibição no ordenamento. A interpretação que vêm sendo consolidada pelos nossos Tribunais defende a ótica de que não se deve ignorar os princípios norteadores da Lei Maior, que consagram a igualdade em seu artigos 3. ${ }^{\circ}$, IV e 5. $\mathrm{em}$ detrimento da discriminação preconceituosa. Independentemente das teses enunciadas pelos diversos pretórios, é uníssono o repúdio da jurisprudência pátria à negativa aos companheiros homossexuais dos direitos que são ordinariamente concedidos aos parceiros de sexos diversos. O companheiro homossexual concorre igualmente com os demais dependentes referidos no art. 16, inciso I, da Lei 8.213/91, assim como o cônjuge divorciado, separado judicialmente ou de fato que recebia pensão de alimentos. A jurisprudência do E. STJ já firmou o posicionamento de que, na hipótese versada nos autos, a pensão vitalícia deve ser repartida em partes iguais entre a ex-esposa do servidor falecido e a companheira, que com ele vivia em união estável, por ocasião do seu falecimento. [...]. (Apelação Cível N 2004.71.07.006747-6/RS, Terceira Turma, TFR $4^{\text {a }}$ Região, Relator: Vânia Hack De Almeida, Julgado em 21/11/2006). (Grifou-se) 
CONSTITUCIONAL PREVIDENCIÁRIO. PENSÃO POR MORTE. CONCESSÃO. COMPANHEIRO. UNIÃO HOMOSSEXUAL. REALIDADE FÁTICA. TRANSFORMAÇÕES SOCIAIS. EVOLUÇÃO DO DIREITO. PRINCÍPIOS CONSTITUCIONAIS DE IGUALDADE. ARTIGOS $3^{\circ}$, IV E $5^{\circ}$. DEPENDÊNCIA ECONÔMICA PRESUMIDA. CORREÇÃO MONETÁRIA. JUROS DE MORA. HONORÁRIOS ADVOCATÍCIOS. 1. A realidade social atual revela a existência de pessoas do mesmo sexo convivendo na condição de companheiros, como se casados fossem. 2. O vácuo normativo não pode ser considerado obstáculo intransponível para o reconhecimento de uma relação jurídica emergente de fato público e notório. 3. O princípio da igualdade consagrado na Constituição Federal de 1988, inscrito nos artigos $3^{\circ}$, IV, e $5^{\circ}$, aboliram definitivamente qualquer forma de discriminação. 4. A evolução do direito deve acompanhar as transformações sociais, a partir de casos concretos que configurem novas realidades nas relações interpessoais. 5. A dependência econômica do companheiro é presumida, nos termos do $\S 4^{\circ}$ do art. 16 da Lei $n^{\circ}$ 8.213/91. 6. Estando comprovada a qualidade de segurado do de cujus na data do óbito, bem como a condição de dependente do autor, tem este o direito ao benefício de pensão por morte, o qual é devido desde a data do ajuizamento da ação, uma vez que o óbito ocorreu na vigência da Lei $n^{\circ}$ 9.528/97. [...] (Apelação Cível N 2000.04.01.073643-8/RS, Sexta Turma, TFR 4ª Região, Relator: Juiz Nylson Paim de Abreu, Julgado em 21/11/2000).

Com as jurisprudências acima e com outras tantas no mesmo sentido, evidencia-se a preocupação de alguns juristas com a aplicação das normas constitucionais, e o comprometimento dos mesmos com os princípios que norteiam a ordem jurídica nacional. Porém, este entendimento ainda é minoritário. Contudo, percebe-se que com a evolução do pensamento jurisprudencial, as decisões estão caminhando para este sentido.

A solução para muitos dos problemas atuais pode ser a intensificação de pensamentos como os dos julgados apresentados. É extremamente necessário que esta tendência dos Tribunais e Juízes Singulares, de interpretação principiológica e constitucional das normas jurídicas, aumente a ponto de tornar-se a forma utilizada por todos para ver e fazer o Direito.

\section{CONSIDERAÇÕES FINAIS}

A existência de relacionamentos homoafetivos é inegável e cada vez mais presente na atualidade. O Direito, como pacificador dos conflitos sociais deve regular vida em sociedade, deve ter a preocupação de tratar de forma equânime todos os indivíduos, de modo a não excluir algumas pessoas de sua proteção. Desta feita, não pode o Direito fechar os olhos à realidade e deixar regular o relacionamento entre 
pessoas do mesmo sexo. Ao proceder desta forma o Estado está sendo negligente com seus representados e não cumpre com os fins do próprio Estado, quais sejam: igualdade, dignidade, liberdade, bem-estar dentre outros princípios elencados no Preâmbulo da Constituição Federal.

A falta de menção expressa ao companheiro homossexual na legislação previdenciária não autoriza o juiz a decidir de forma desigual, gerando injustiças. Todo o magistrado, ao traçar uma solução aos conflitos dos indivíduos, deve orientá-la segundo os princípios constitucionais, respeitando a unidade e harmonia do ordenamento jurídico.

Desta maneira, estar-se-á caminhando para uma sociedade mais justa, igualitária, na qual cada vez menos haverá espaço para preconceitos de qualquer gênero. Estar-se-á confirmando o fundamento do próprio Estado Democrático de Direito.

\section{REFERÊNCIAS BIBLIOGRÁFICAS}

BASTOS, Celso Ribeiro. Hermenêutica e Interpretação Constitucional. $3^{\text {a }}$ edição. São Paulo: Ed Celso Bastos, 2002. p.141.

GARCIA DE ENTERRÍA, Eduardo. Princípio da legalidade na constituição espanhola apud: MORAES, Alexandre de. Direito Constitucional. 19a edição. São Paulo: Atlas, 2006. p.36.

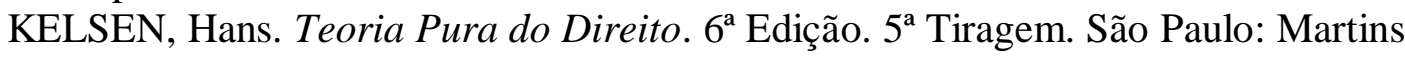
Fontes, 2003. p.387-8.

KERTZMAN, Ivan Mascarenhas. Curso prático de Direito Previdenciário direcionado para concursos. Salvador: Jus PODIVM, 2005. p.263.

MORAES, Alexandre de. Direito Constitucional. 19a edição. São Paulo: Atlas, 2006. p.36.

PEDRA, Anderson Sant'Ana. Os fins sociais da norma e os princípios gerais de direito. Artigo disponível em <http://jus2.uol.com.br/doutrina/texto.asp?id=3762>. Visitado em 04/10/2007.

Tribunal de Justiça do RS, Sentença, Foro Central de Porto Alegre, $2^{\text {a }}$ Vara de Família e Sucessões. Juiz Roberto Arriada Lorea, Julgado em 14/02/2005

<http://www.tj.rs.gov.br/site_php/noticias/mostranoticia.php?assunto=1\&categoria=1\&i tem=30873>. Visitado em 12/09/2007.

Tribunal de Justiça do RS, Apelação Cível No 599348562, Oitava Câmara Cível, Relator: Antônio Carlos Stangler Pereira, Julgado em 11/10/2001. Disponível em <http://www.tj.rs.gov.br/site_php/jprud2/ementa.php>. Visitado em 05/10/2007. Tribunal de Justiça do RS, Apelação Cível No 70009888017, Sétima Câmara Cível, Relator: Sérgio Fernando de Vasconcellos Chaves, Julgado em 27/04/2005. Disponível em <http://www.tj.rs.gov.br/site_php/jprud2/ementa.php>. Visitado em 05/10/2007. TFR 4 ${ }^{a}$ Região, Agravo de Instumento N ${ }^{\circ} 2000.04 .044144-0$. Sexta Turma, Relator: Luiz Carlos de Castro Lugon, Julgado em 27/06/2000 <http://www.trf4.gov.br/trf4/jurisjud/resultado_pesquisa.php>. Visitado em 05/10/2007. 
TFR 4 ${ }^{a}$ Região, Apelação Cível N 2005.71.10.001969-0/RS, Sexta Turma, Relator: Des. Federal João Batista Pinto Silveira, Julgado em 28/02/2007

<http://www.trf4.gov.br/trf4/jurisjud/resultado_pesquisa.php>. Visitado em 05/10/2007. TRF 4 ${ }^{a}$ Região, Apelação Cível N ${ }^{\circ}$ 2000.04.01.073643-8, Sexta Turma, Relator Nylson Paim de Abreu, Publicado em 10/01/2001

<http://www.trf4.gov.br/trf4/jurisjud/resultado_pesquisa.php>. Visitado em 05/10/2007. TFR 4ª Região, Apelação Cível N 2004.71.07.006747-6/RS, Terceira Turma, Relator: Vânia Hack De Almeida, Julgado em 21/11/2006

<http://www.trf4.gov.br/trf4/jurisjud/resultado_pesquisa.php>. Visitado em 05/10/2007. TFR 4ª Região, Apelação Cível N 2000.04.01.073643-8/RS, Sexta Turma, Relator: Juiz Nylson Paim de Abreu, Julgado em 21/11/2000 <http://www.trf4.gov.br/trf4/jurisjud/resultado_pesquisa.php>. Visitado em 05/10/2007. BRASIL. Constituição (1988). Constituição da República Federativa do Brasil. Brasília, DF, Senado, 1988.

BRASIL. Código Civil - Lei 10.406, de 10 de janeiro de 2002. Institui o Código Civil. BRASIL, Lei de Introdução ao Código Civil Brasileiro - Decreto-lei 4.657, de 04 de setembro de 1942. (LICC).

BRASIL, Lei dos Benefícios Previdenciários - Lei 8.213, de 24 de julho de 1991. Dispõe sobre os Planos de Benefícios da Previdência Social e dá outras providências. 
